\title{
Bloody white cells-no problem: Let's solve hemorrhage out of the operating room
}

\author{
Simon C. Body, MBChB, MPH, FAHA
}

See related article on pages 216-22.

In this issue of the Journal, McQuilten and colleagues ${ }^{1}$ report the effects of the introduction of universal leukodepletion of red blood cells on patient outcomes after cardiac surgery. Whole blood and red blood cell (WBRBC) units and units of apheresis platelets are usually leukocyte depleted to decrease the perceived risk of febrile nonhemolytic reactions, leukotropic virus infection such as cytomegalovirus (CMV), and HLA alloimmunization. ${ }^{2}$ Leukodepleted units have less than 0.83 million leukocytes per WB-RBC unit and less than 5 million leukocytes per unit of apheresis platelets. Universal prestorage leukodepletion of red blood cell and platelet products was instituted by the Canadian Blood Services by 1999, was put into practice in Australia in 2008, and is currently the practice in most European countries.

The majority of WB-RBC units transfused in the United States are leukocyte depleted, but not all are. The biannual United States National Blood Collection and Utilization Survey for $2011^{3}$ reported that $84.8 \%$ of the $13,785,000$ WB-RBC units transfused in the United States in 2011 and $86.6 \%$ of the $2,179,000$ unit equivalents of apheresis platelets were leukocyte depleted. Apheresis platelets are leukocyte depleted by the method of collection, so it is likely that their rate was $100 \%$ but that reporting was incomplete. The rate of leukocyte depletion at the bedside has declined to nearly zero. Of the institutions that responded to the United States National Blood Collection and Utilization Survey of 2011, $73 \%$ reported that they had a policy of transfusing only leukocyte-depleted components. Of the remaining institutions, fewer than $3 \%$ reported that they transfused only leukocyte-depleted components to cardiac surgical patients. $^{3}$ It is therefore likely that about $2,000,000$

\footnotetext{
From the Department of Anesthesiology, Perioperative and Pain Medicine, Brigham and Women's Hospital, Harvard Medical School, Boston, Mass.

Disclosures: Author has nothing to disclose with regard to commercial support.

Received for publication April 2, 2015; accepted for publication April 3, 2015; available ahead of print May 2, 2015.

Address for reprints: Simon C. Body, MBChB, MPH, FAHA, Department of Anesthesiology, Perioperative and Pain Medicine, Brigham and Women's Hospital, 75 Francis St, Boston, MA 02115 (E-mail: sbody@partners.org).

J Thorac Cardiovasc Surg 2015;150:223-4

$0022-5223 / \$ 36.00$

Copyright (c) 2015 by The American Association for Thoracic Surgery

http://dx.doi.org/10.1016/j.jtcvs.2015.04.001
}

leukocyte-rich WB-RBC units are still transfused in the United States each year.

Leukocyte depletion may have some effect on the risks of febrile nonhemolytic reactions, transmission of CMV, and HLA alloimmunization, but it is not entirely clear how effective universal leukocyte depletion is in preventing these adverse events. ${ }^{4}$ The

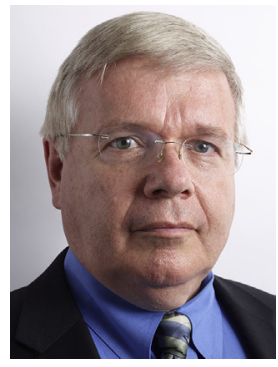
rates of adverse transfusion reaction and of severe adverse donor reactions in the United States during the last 15 years have remained steady, at $0.24 \%$ and $0.13 \%$, respectively. Febrile nonhemolytic reactions occurred at a rate of 1 reaction per 957 units of any blood component transfused. Current data for the rate for only red blood cell-containing products is unavailable. Similarly, current data for reduction in CMV infection and HLA alloimmunization after WB$\mathrm{RBC}$ or platelet transfusion are also not available. CMV infection is a greater risk for patients who are immunosuppressed hand have no evidence of CMV resistance, such as CMV-seronegative bone marrow and organ transplant recipients and neonates with an anti-CMV-seronegative mother. Lastly, HLA alloimmunization - the development of anti-HLA antibodies-induced by leukocyte-rich transfusion may be ameliorated by leukodepletion. Thus patients who are likely to receive heart, bone marrow, or other transplant should routinely receive leukocyte-depleted units.

Cardiac surgeons, however, generally worry most about nonspecific proinflammatory immune modulation by transfused leukocytes, notably possible effects on end-organ dysfunction, infection, and mortality. As detailed in the article of McQuilten and colleagues, ${ }^{1}$ the evidence that immune modulation by transfused leukocytes has an effect on clinical outcomes is weak, or at best controversial, and this article adds another tick to the "no" column. The observed reduction in acute kidney injury may be a specific effect of leukodepletion, or it may mirror the overall reduction in adverse events and mortality observed during the 2000s. It does not appear enough on its own to justify leukodepletion. It is hard to get too worried, however, because the technology is cheap and effective for leukodepletion, even if the benefit is marginal, and its use is generally routine for most transfusions.

There is another way of looking at the value or lack thereof of leukodepletion. If there is no need to transfuse because you have been effective at reducing blood wastage, then no one need care whether an untransfused unit is leukodepleted or not. There are 2 sources of avoidable 
blood loss out of the operating room that can be favorably impacted by cardiac surgeons.

Avoidance of the usual approximately 5\% reduction in hematocrit after femoral cardiac catheterization and the occasional but significant risk of femoral access site bleeding complications should be possible by a change to performing radial instead of femoral cardiac catheterization. ${ }^{5}$ The primary advantage of transradial cardiac catheterization is reduced access site bleeding, as opposed to the sometimes catastrophic complications associated with femoral arterial cannulation, along with decreased cost and patient burden. ${ }^{6-}$ ${ }^{8}$ There are concerns with a steep learning curve, ${ }^{9}$ cannulation difficulty, technical issues with coronary artery engagement, use of the radial artery for subsequent coronary revascularization, and ischemic hand complications; however, these concerns should not limit the use of radial cannulation for most cardiac catheterization procedures. ${ }^{10,11}$ Although radial catheterization is common, ${ }^{12}$ it is not routine in every US institution; however, it is a valuable means of transfusion avoidance. It is time to encourage our interventional colleagues.

The volume of blood used for laboratory testing in association with cardiac surgical procedures is an unmeasured and little-recognized source of blood loss. This is not a new idea, ${ }^{13}$ but large-volume blood sampling, equivalent to a unit of whole blood for routine cardiac surgery, persists even the most sophisticated centers. ${ }^{14}$ What would happen if $1.5-\mathrm{mL}$ phlebotomy tubes were routinely used instead for all perioperative testing? The technology has no additional cost, may have benefit, and can easily be routine for all patients.

\section{References}

1. McQuilten ZK, Andrianopoulos N, van de Watering L, Aubron C, Phillips L, Bellomo R, et al. Introduction of universal prestorage leukodepletion of blood components and outcomes in transfused cardiac surgery patients. J Thorac Cardiovasc Surg. 2015;150:216-22.

2. Pruss A, Kalus U, Radtke H, Koscielny J, Baumann-Baretti B, Balzer D, et al. Universal leukodepletion of blood components results in a significant reduction of febrile non-hemolytic but not allergic transfusion reactions. Transfus Apher Sci. 2004:30:41-6.

3. Whitaker BI, Hinkins S. The 2011 national blood collection and utilization survey report [Internet]. Bethesda (MD): United States Department of Health and Human Services; 2011 [cited 2015 Mar 28]. Available at:, http://www.hhs. gov/ash/bloodsafety/2011-nbcus.pdf.

4. Spencer S, Tang A, Khoshbin E. Leukodepletion for patients undergoing heart valve surgery. Cochrane Database Syst Rev. 2013;7:CD009507.

5. Jolly SS, Yusuf S, Cairns J, Niemelä K, Xavier D, Widimsky P, et al; RIVAL trial group. Radial versus femoral access for coronary angiography and intervention in patients with acute coronary syndromes (RIVAL): a randomised, parallel group, multicentre trial. Lancet. 2011;377:1409-20. Erratum in: Lancet. 2011;378:30. Erratum in: Lancet. 2011;377:1408.

6. Joyal D, Bertrand OF, Rinfret S, Shimony A, Eisenberg MJ. Meta-analysis of ten trials on the effectiveness of the radial versus the femoral approach in primary percutaneous coronary intervention. Am J Cardiol. 2012; 109:813-8.

7. Mitchell MD, Hong JA, Lee BY, Umscheid CA, Bartsch SM, Don CW. Systematic review and cost-benefit analysis of radial artery access for coronary angiography and intervention. Circ Cardiovasc Qual Outcomes. 2012;5:454-62.

8. Spertus JA, Decker C, Gialde E, Jones PG, McNulty EJ, Bach R, et al. Precision medicine to improve use of bleeding avoidance strategies and reduce bleeding in patients undergoing percutaneous coronary intervention: prospective cohort study before and after implementation of personalized bleeding risks. BMJ. 2015;350:h1302.

9. Hess CN, Peterson ED, Neely ML, Dai D, Hillegass WB, Krucoff MW, et al. The learning curve for transradial percutaneous coronary intervention among operators in the United States: a study from the National Cardiovascular Data Registry. Circulation. 2014;129:2277-86.

10. Agostoni P, Biondi-Zoccai GG, de Benedictis ML, Rigattieri S, Turri M, Anselmi M, et al. Radial versus femoral approach for percutaneous coronary diagnostic and interventional procedures; systematic overview and meta-analysis of randomized trials. J Am Coll Cardiol. 2004;44:349-56.

11. Barbash IM, Minha S, Gallino R, Lager R, Badr S, Loh JP, et al. Operator learning curve for transradial percutaneous coronary interventions: implications for the initiation of a transradial access program in contemporary US practice. Cardiovasc Revasc Med. 2014;15:195-9.

12. Feldman DN, Swaminathan RV, Kaltenbach LA, Baklanov DV, Kim LK, Wong SC, et al. Adoption of radial access and comparison of outcomes to femoral access in percutaneous coronary intervention: an updated report from the National Cardiovascular Data Registry (2007-2012). Circulation. 2013; 127:2295-306.

13. Smoller BR, Kruskall MS, Horowitz GL. Reducing adult phlebotomy blood loss with the use of pediatric-sized blood collection tubes. Am J Clin Pathol. 1989;91: 701-3.

14. Koch CG, Reineks EZ, Tang AS, Hixson ED, Phillips S, Sabik JF III, et al. Contemporary bloodletting in cardiac surgical care. Ann Thorac Surg. 2015; 99:779-84. 